\title{
Total anomalous systemic venous drainage to coronary sinus
}

\author{
Ashish Agarwal, Navin Agrawal, Soumya Patra, C N Manjunath
}

Deapartment of Cardiology, Sri Jayadeva Institute of Cardiovacular Sciences and Research, Bengaluru, Karnataka, India

\section{Correspondence to} Dr Navin Agrawal,

drnavinagrawal@gmail.com

\section{DESCRIPTION}

Congenital anomalies of the systemic venous return forms a spectrum of malformations with a diverse physiological consequence ${ }^{1}$ which may occur independently or as part of complex isomerisms. ${ }^{2}$

We report a case of a 12-year-old boy, who had history undergone percutaneous balloon coarctoplasty a year previously at a different centre of which specific procedure-related details were not available, and presented for routine follow-up at our centre. He was asymptomatic with an arterial saturation of $98 \%$. Transthoracic echocardiography revealed situs solitus with the aorta and hemiazygous vein on the left side of the spine and absence of the inferior vena cava (IVC) (figure 1). Hepatic veins were draining directly into the right atrium (RA) and aorta and hemiazygous veins were arranged in an anteroposterior orientation (figure 1). The right superior vena cava (SVC) was absent and a dilated coronary sinus (CS) was draining into RA (figure 2, videos 1 and 2). The right internal jugular vein and subclavian vein were draining into the left superior vena cava (LSVC) by forming innominate veins. The left parasternal view showed the hemiazygous vein ascending up into the thorax behind the aorta and coursing anteriorly to join LSVC $\rightarrow$ CS $\rightarrow$ RA (figure 3, videos 3 and 4). There were no intracardiac anomalies. A suprasternal view showed the absence of any significant gradient in the descending thoracic aorta. A conservative management was planned.

The literature on TASVR, especially in cases having drainage to the CS, is limited to anecdotal case reports only. ${ }^{3}$ Though the lynchpin of the diagnosis of TASVR lies on angiography, echocardiography can also be used to detect a persistent left SVC which is the most common of these, while other anomalies like the absence of IVC, right SVC and hepatic venous drainage can also be picked up.

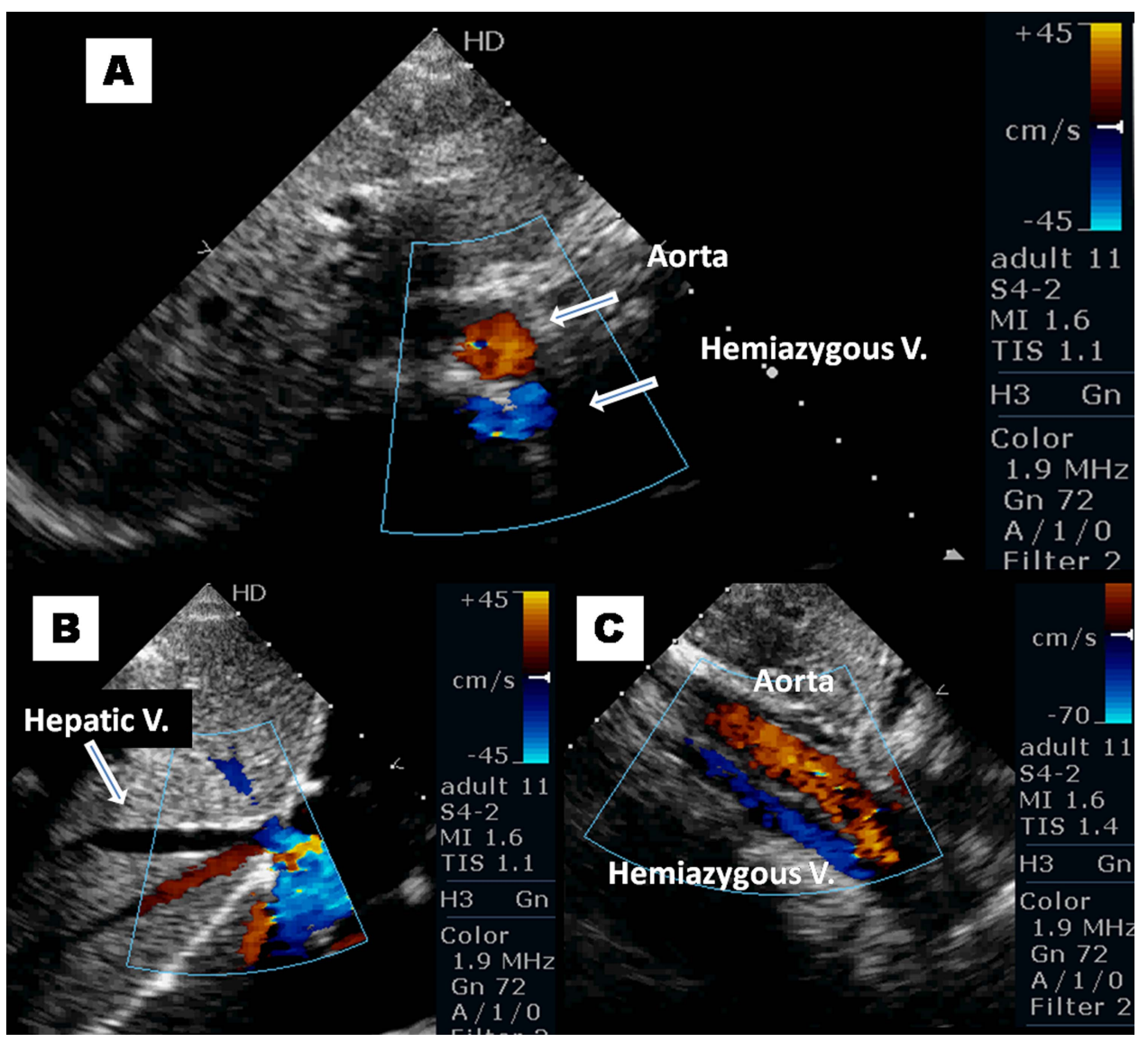

Figure 1 Subcostal views. (A) Short axis view with colour Doppler showing situs solitus. Aorta and hemiazygous vein on the left side of the spine and an absent inferior vena cava. (B) Long-axis view with colour Doppler showing hepatic veins are directly draining into right atrium. (C) Long-axis view with tilting the probe to the left side showing anteroposterior arrangement of the aorta (anterior) and hemiazygous vein (posterior). 


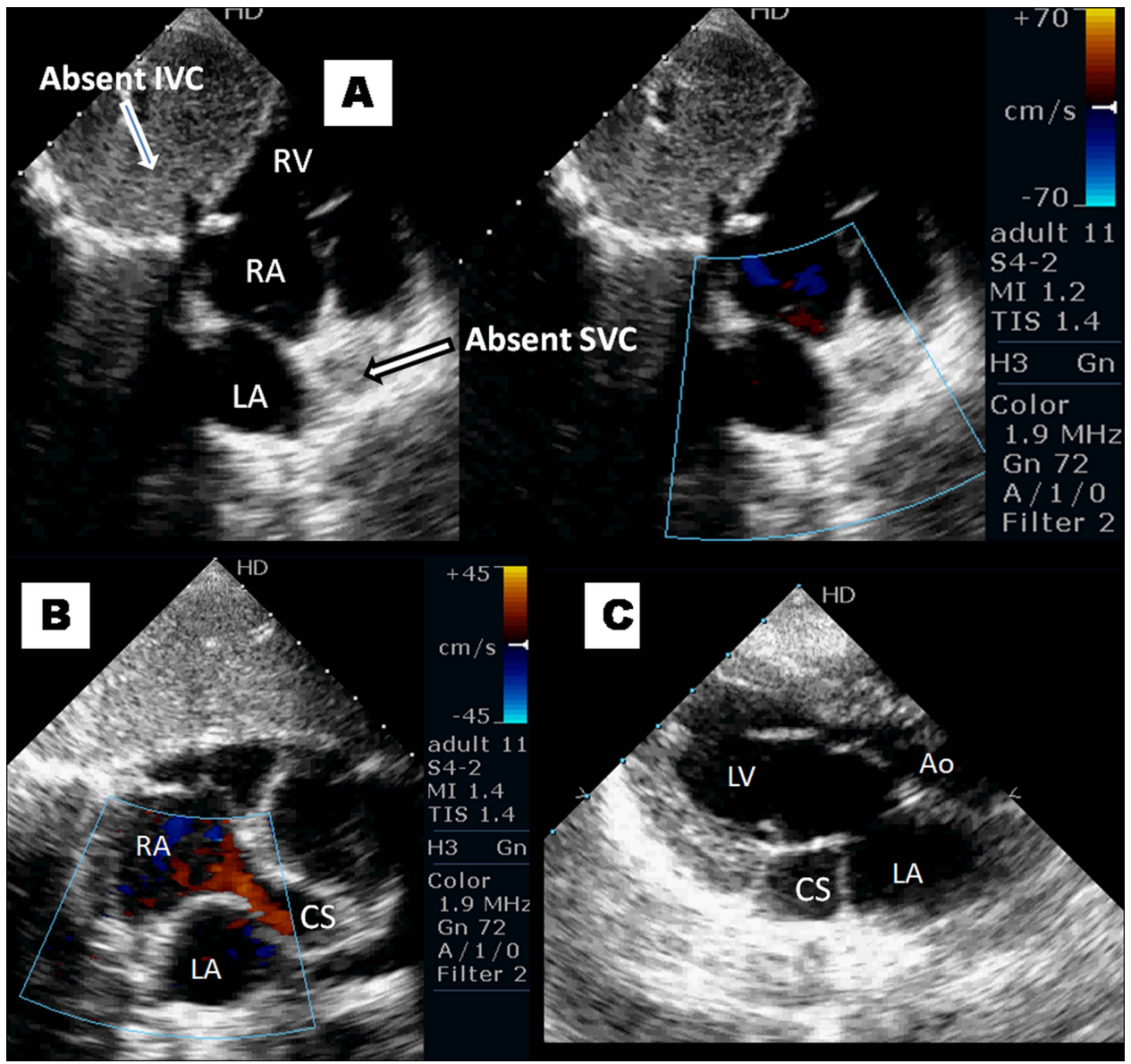

Figure 2 (A) Subcostal saggital view with colour compare of images with probe direction towards left atrium and right atrium (RA) showing the absence of inferior vena cava and superior vena cava (SVC). (B) Subcostal coronal view with posterior tilt showing dilated coronary sinus draining into RA with an absent SVC flow. (C) Parasternal long-axis view showing dilated coronary sinus (CS).

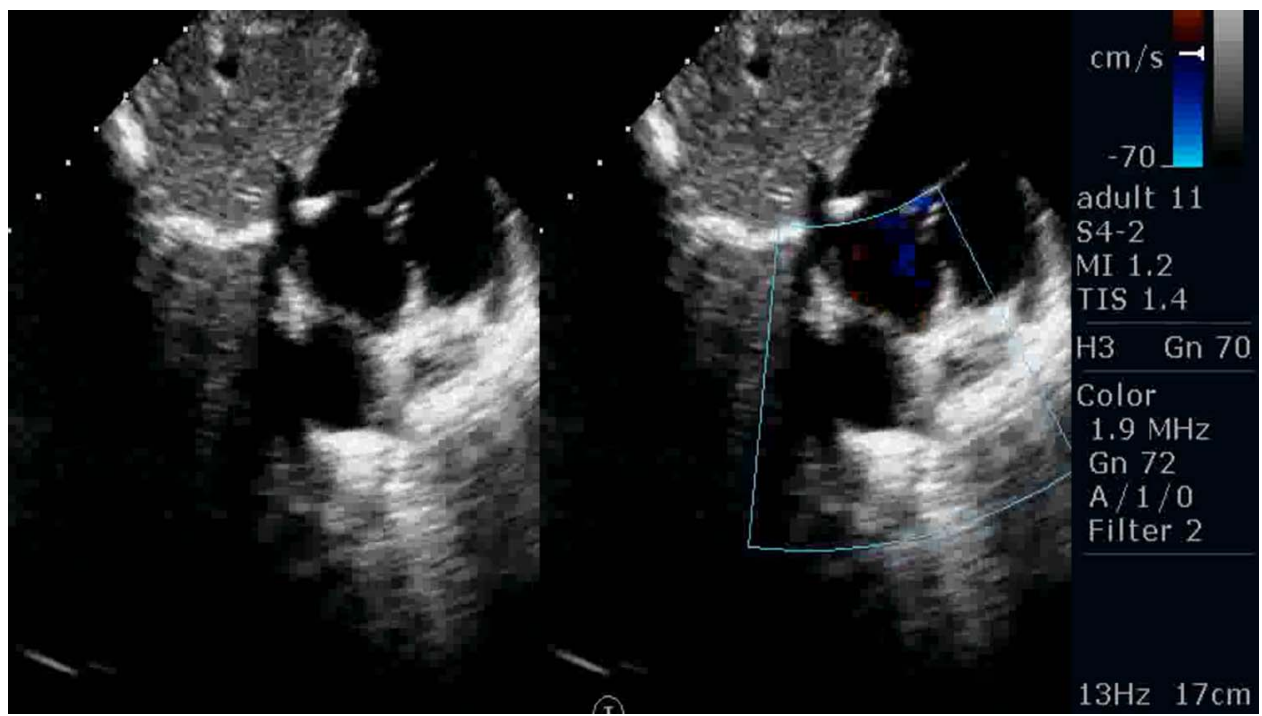

Video 1 Subcostal saggital view with color compare with probe direction towards LA and RA shows absence of IVC and SVC. 


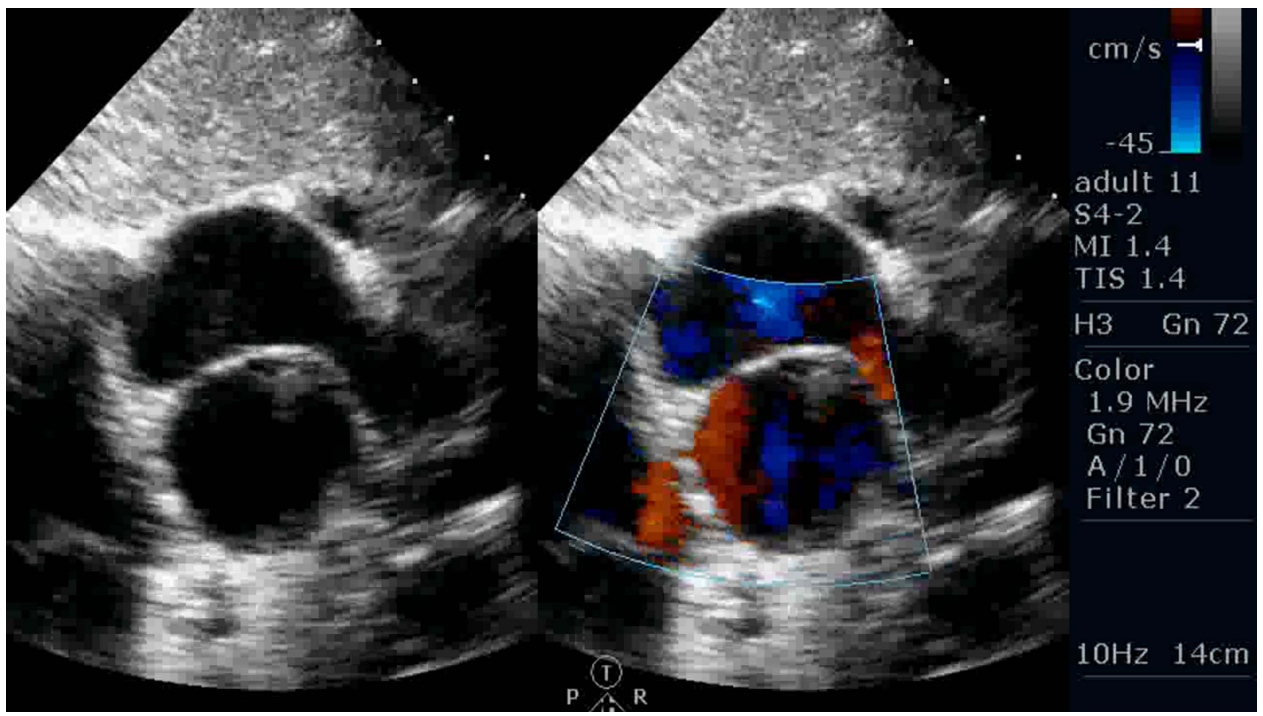

Video 2 Subcostal coronal view with posterior tilt shows dilated coronary sinus draining into RA with absent SVC flow.

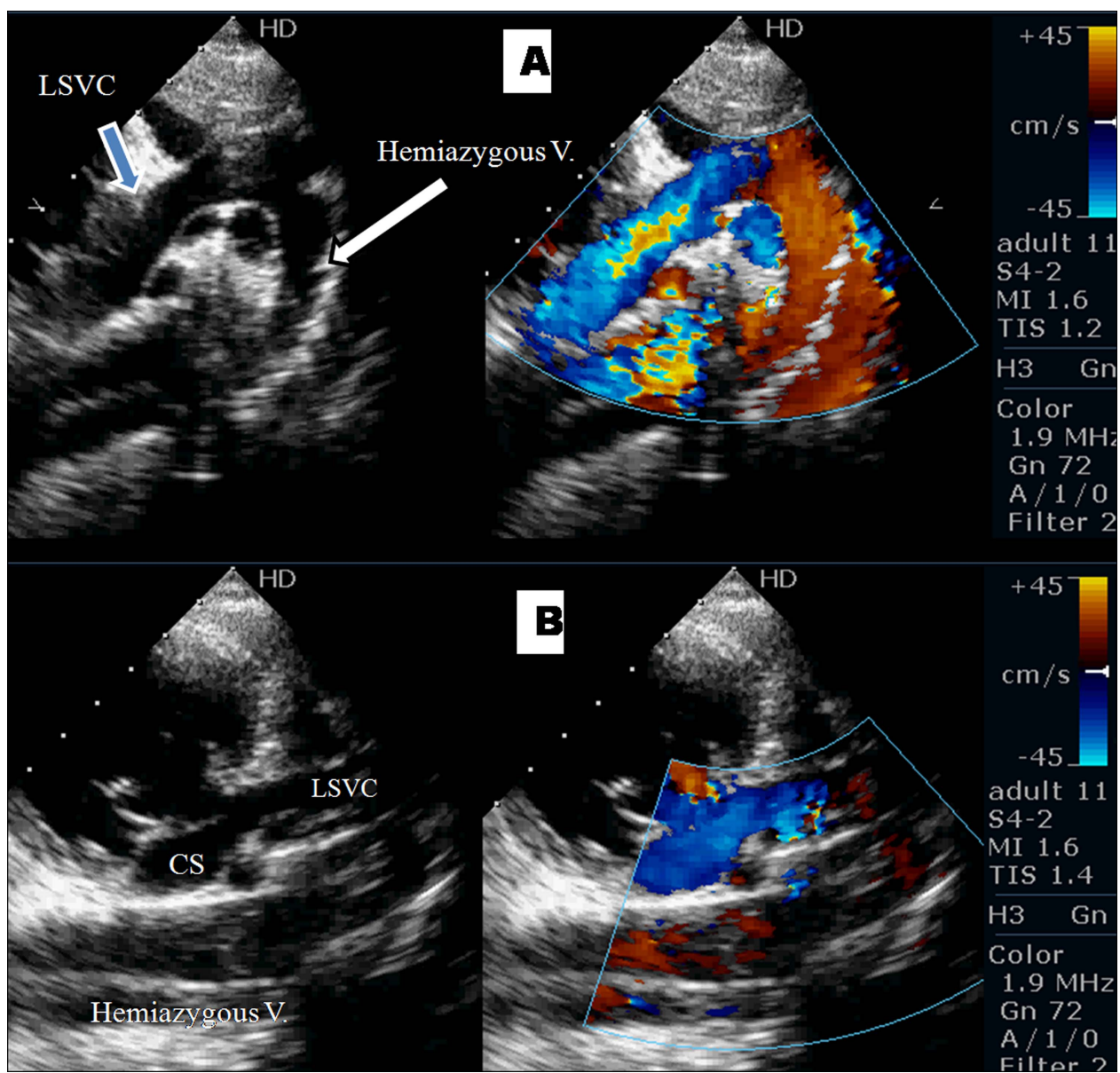

Figure 3 (A) Modified high left parasternal view with colour compare of images showing hemiazygous vein ascending up in the thorax behind aorta and draining into the left superior vena cava (LSVC). (B) Modified left lower parasternal view with colour compare of the image showing hemiazygous vein coursing anteriorly and draining in to LSVC, which eventually is draining into coronary sinus (CS). 


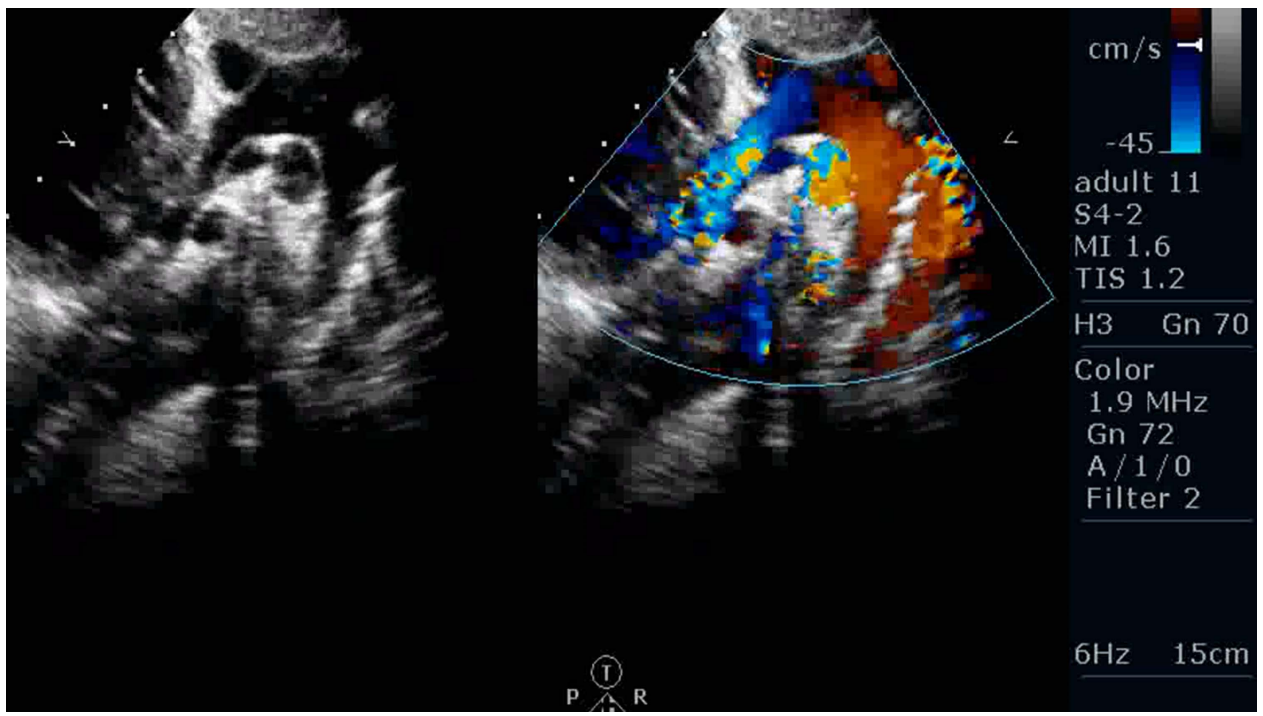

Video 3 Modified high left Parasternal view with color compare shows Hemiazygous vein ascending up in the thorax behind aorta and draining into LSVC.

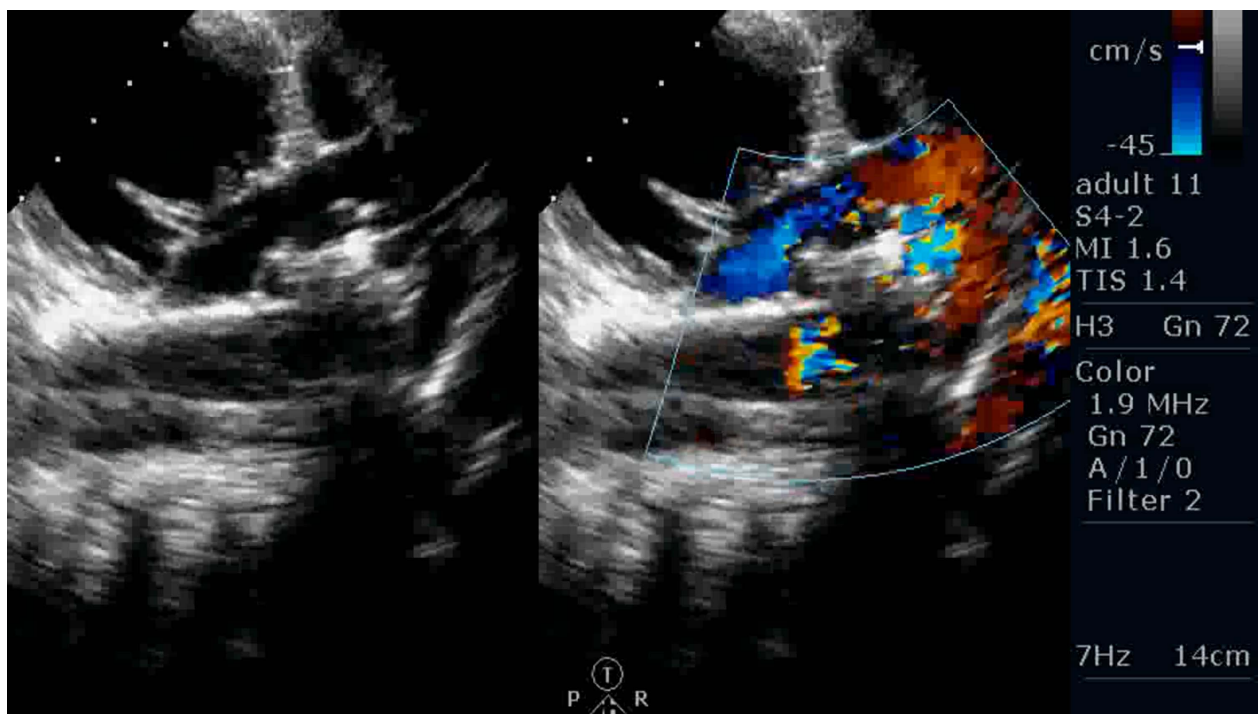

Video 4 Modified left lower Parasternal view with color compare shows Hemiazygous vein coursing anteriorly and draining in to LSVC, which eventually is draining into CS.

\section{Learning points}

- TASVR is a rare anomaly with diverse physiological consequences ranging from being clinically insignificant to a large right-to-left shunt with systemic arterial desaturation needing surgical repair.

- Repair is usually indicated only if the anomaly is haemodynamically significant or is associated with other complex cardiac anomalies warranting repair.

- Angiography is the mainstay of diagnosis of TASVR; echocardiography is especially useful in the detection of persistent left superior vena cava which is the most common form of systemic venous anomaly and other forms of TASVR.
Contributors All the authors have contributed to the drafting of the manuscript and have helped in patient care.

Competing interests None.

Patient consent Obtained.

Provenance and peer review Not commissioned; externally peer reviewed.

\section{REFERENCES}

1 Devendran V, Varghese R, Gudeboyana K, et al. Isolated total anomalous systemic venous drainage in an adult: case report. Pediatr Cardiol 2013;34: 1918-21.

2 Mazzucco A, Bortolotti U, Stellin G, et al. Anomalies of the systemic venous return: a review. J Card Surg 1990;5:122-33.

3 Kadletz M, Black MD, Smallhorn J, et al. Total anomalous systemic venous drainage to the coronary sinus in association with hypoplastic left heart disease: more than a mere coincidence. J Thorac Cardiovasc Surg 1997:114:282-4. 
Copyright 2013 BMJ Publishing Group. All rights reserved. For permission to reuse any of this content visit http://group.bmj.com/group/rights-licensing/permissions.

BMJ Case Report Fellows may re-use this article for personal use and teaching without any further permission.

Become a Fellow of BMJ Case Reports today and you can:

- Submit as many cases as you like

- Enjoy fast sympathetic peer review and rapid publication of accepted articles

- Access all the published articles

- Re-use any of the published material for personal use and teaching without further permission

For information on Institutional Fellowships contact consortiasales@bmjgroup.com

Visit casereports.bmj.com for more articles like this and to become a Fellow 